\title{
TECNOLOGIA ASSISTIVA: um protótipo colaborativo para auxiliar pessoas com surdez.
}

\author{
Jessica da Silva Araujo ${ }^{1}$, Zenaide Carvalho da Silva ${ }^{1}$ \\ ${ }^{1}$ Universidade Federal do Sul e Sudeste do Pará (UNIFESSPA) \\ Folha 17, Quadra 04, Lote Especial - 68505-080 - Marabá - PA - Brasil \\ \{jessicaaraujo, zenaide.slva\}@unifesspa.edu.br
}

\begin{abstract}
This work carried out a survey of the assistive technologies existing in the Multifunctional Resource Rooms of three elementary schools in the municipality of Marabá-PA between the years 2016 and 2018. Based on this verification, a prototype of a mobile application called EduLib was developed for assisting people in the area of deafness, using sign language to collaborate with professionals working in the Multifunctional Resource Rooms when they receive deaf people in these rooms, the preliminary results are presented in this article.
\end{abstract}

Resumo. Este trabalho realizou um levantamento das tecnologias assistivas existentes nas Salas de Recursos Multifuncionais de três Escolas do Ensino Fundamental do município de Marabá-PA entre os anos de 2016 e 2018. Com base nesta verificação, foi elaborado um protótipo de um aplicativo móvel chamado EduLib para auxiliar pessoas na área da surdez, com o emprego da linguagem de sinais para colaborar com os profissionais que atuam nas Salas de Recursos Multifuncionais quando eles recebem pessoas com surdez nessas salas, os resultados preliminares são apresentados neste artigo.

\section{Introdução}

As Salas de Recursos Multifuncionais (SRMF) são salas especiais instaladas dentro das escolas com o objetivo em auxiliar crianças com necessidades especiais, é um local que se executam procedimentos educacionais utilizando vários tipos de materiais, entre eles, os equipamentos como computadores, teclados, monitores, mouses e softwares ou qualquer ferramentas que sejam produzidas de acordo com as necessidades dos alunos para a realização do Atendimento Educacional Especializado (AEE) [Moscardini 2011].

A terminologia Tecnologia Assistiva (TA) foi criada em 1988 nos Estados Unidos como forma de promover direitos as pessoas com necessidades especiais, onde abriu portas para vários recursos e produtos adaptados como inclusão cidadã [Rocha 2010].

A tecnologia vem conquistando o mundo de forma abrangente em todas as áreas dentro da sociedade, por este motivo, a tecnologia assistiva foi escolhida para demonstrar como ajudar as pessoas com necessidades, e também as pessoas que estão ao redor.

Nesse contexto, no município de Marabá-PA foram realizadas dois levantamentos em três escolas nos anos de 2016 e 2018, para verificar a adoção dos recursos de tecnologia assistiva, demonstrando as mudanças que foram realizadas nas 
VII Congresso Brasileiro de Informática na Educação (CBIE 2018)

Anais dos Workshops do VII Congresso Brasileiro de Informática na Educação (WCBIE 2018)

Salas de Recursos Multifuncionais destas escolas durante este período em questão, referentes às tecnologias existentes e adotadas nestas salas.

A tecnologia fornecida dentro das salas difere de aluno para aluno: crianças com baixa visão, crianças com limitação da comunicação oral, crianças com dificuldade física, crianças intelectuais entre outros.

O que motivou a realização desta pesquisa foi observar a dificuldade dos professores em elaborar atividades adequadas e de acordo com a necessidade e especificidade das crianças com necessidades especiais ao ministrarem as suas aulas, pois, eles são inclusos em conjunto com os outros alunos que não possuem deficiência, percebe-se muitas dificuldades em ministrar uma aula para os alunos com necessidades especiais sem o uso de tecnologias adequadas que possam servir como recurso pedagógico e facilitador da aprendizagem para as crianças.

Baseado na pesquisa realizada nas escolas participantes, foi desenvolvido um protótipo de um aplicativo móvel chamado EduLib, objetivando ser uma ferramenta de apoio simples para auxiliar pessoas surdas com a utilização da linguagem de sinais, e também apoiar os professores que utilizam as SRMF oferecendo um aplicativo que possa apoiar suas atividades realizadas nessas salas no atendimento de alunos surdos.

O presente trabalho está estruturado em 5 seções. A seção 2 apresenta os aplicativos relacionados com a temática pesquisada, na seção 3 é apresentado o aplicativo com as principais telas, a seção 4 apresenta os resultados iniciais obtidos. Por fim, na seção 5 a conclusão.

\section{Aplicativos Relacionados}

Nesta seção vamos destacar alguns aplicativos que se relacionam com a temática em questão, devido aos aspectos de simplicidade e facilidade de acesso os aplicativos relacionados aqui foram pesquisados no Google Play, que é um serviço de distribuição digital de aplicativos [Google Play 2018].

O Fala Libras é um aplicativo simples, onde é possível aprender as palavras básicas da linguagem do alfabeto e das cores em Libras disponível para Sistemas Operacionais Android. Possui duas categorias cores e alfabeto, as funcionalidades via botões correspondem a cada item selecionado, os movimentos das cores são por meio de imagens. A Figura 1 a seguir, mostra a tela principal do aplicativo Fala Libras.

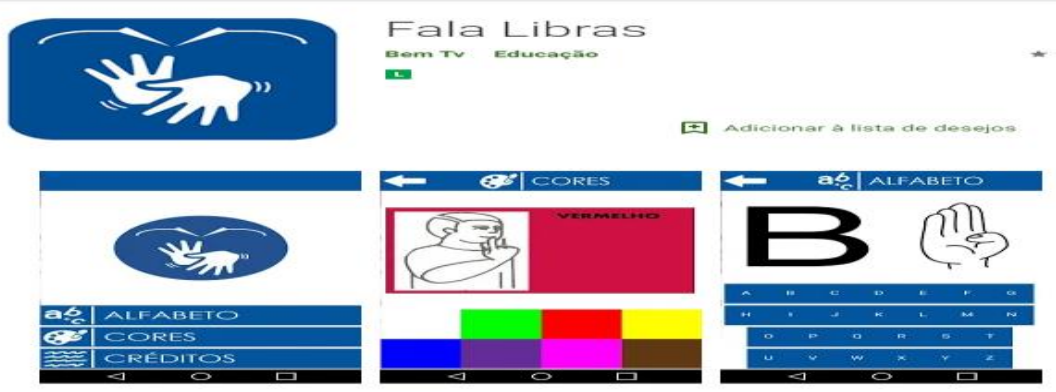

Figura 1. Aplicativo Fala Libras [Google Play 2018].

Os pontos importantes do aplicativo são praticidade e rapidez, entretanto, não possui muitas palavras, sendo um aplicativo para iniciante, criado em 2016 pelo Bem Tv, é um aplicativo Brasileiro de sinais. 
VII Congresso Brasileiro de Informática na Educação (CBIE 2018)

Anais dos Workshops do VII Congresso Brasileiro de Informática na Educação (WCBIE 2018)

O aplicativo Alphabet for deaf-mutes é o alfabeto para surdo na área educacional em Sistemas Operacionais em Android, possui algumas funcionalidades como a utilização de imagens somente do alfabeto, possui rapidez no aprendizado por melhorar a memorização por meio das imagens. A Figura 2 apresenta a tela principal do aplicativo Alphabet for deaf-mutes.

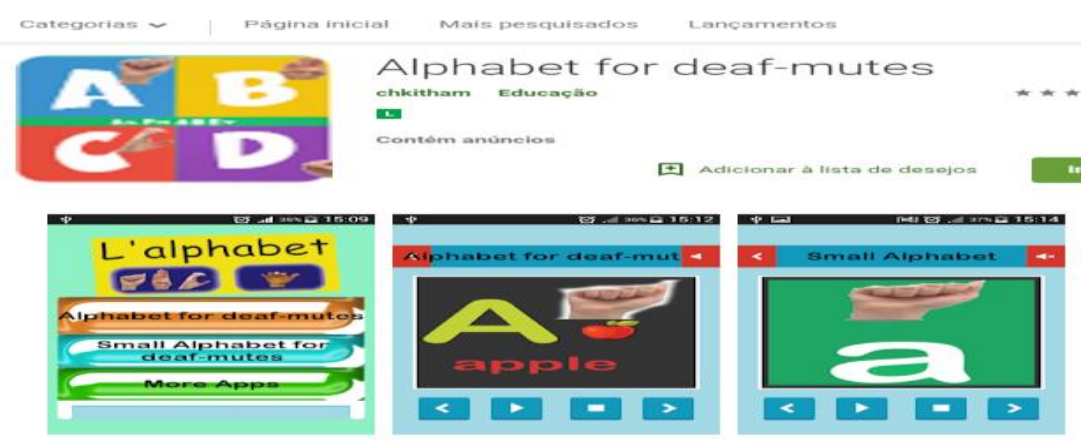

Figura 2. Aplicativo Alphabet for deaf mutes [Google Play 2018].

Este aplicativo foi criado para entender a linguagem de sinais, apresentam os gestos das letras e dispõe de áudio em Inglês falando sobre a imagem relacionada com as iniciais das letras e outro somente da letra em linguagem de sinais. Esse aplicativo também foi pesquisado via Google play.

O Sinalário Disciplinar em Libras é uma ferramenta de apoio para os alunos e os profissionais que trabalham com a educação para pessoas com surdez. Possui as funcionalidades por meio de vídeos das disciplinas do ensino Fundamental e Médio. Ao entrar no menu principal o usuário escolhe a matéria escolar, e logo é designado aos vídeos de sua escolha. A Figura 3 apresenta a tela principal do aplicativo Disciplinar em Libras.
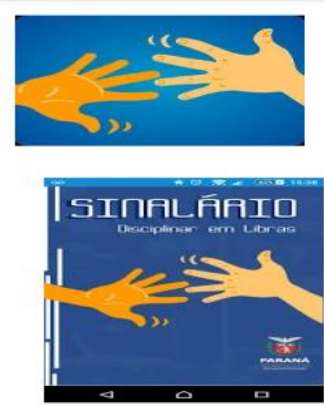
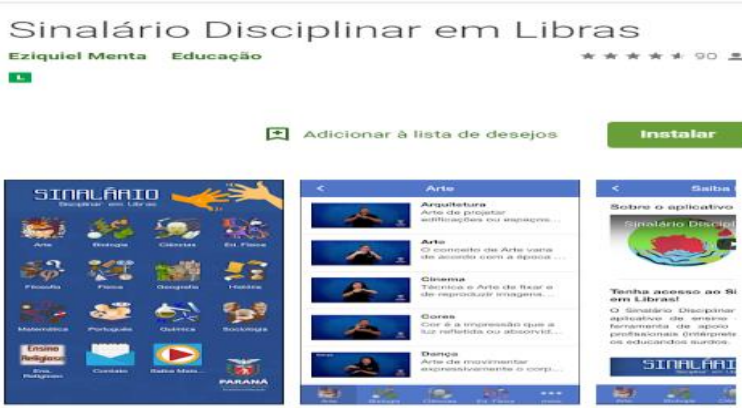

Figura 3. Aplicativo Sinalário Disciplinar em Libras [Google Play 2018].

O aplicativo é indicado para professores e estudantes, mas não possui compatibilidade com todos os tipos de aparelhos de celulares, disponível em Sistema Operacional em Android criado em 2017 por Ezequiel Menta.

O trabalho de Moura e Oliveira (2014) apresenta o aplicativo Glossário que é uma ferramenta de apoio colaborativo ao ensino e aprendizagem da Libras para trabalhos realizados em grupos da disciplina de língua portuguesa com alunos surdos. A ferramenta glossário possui inserção, busca e visualização em ordem alfabética, além de possuir imagens de números em libras para a escolha da categoria desejada. As Figuras 4 e 5 apresentam algumas telas do aplicativo Glossário. 
VII Congresso Brasileiro de Informática na Educação (CBIE 2018)

Anais dos Workshops do VII Congresso Brasileiro de Informática na Educação (WCBIE 2018)

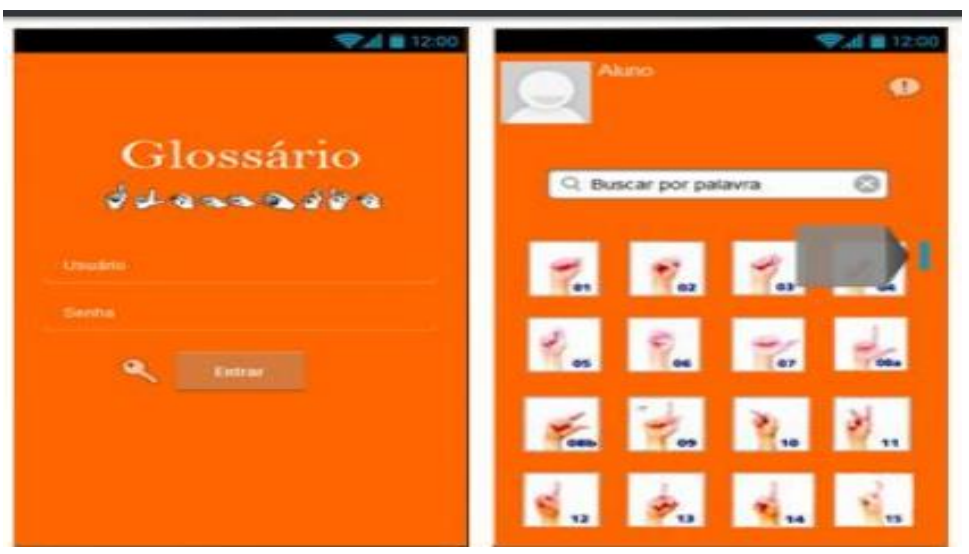

Figura 4. Aplicativo Glossário [Moura e Oliveira 2014]
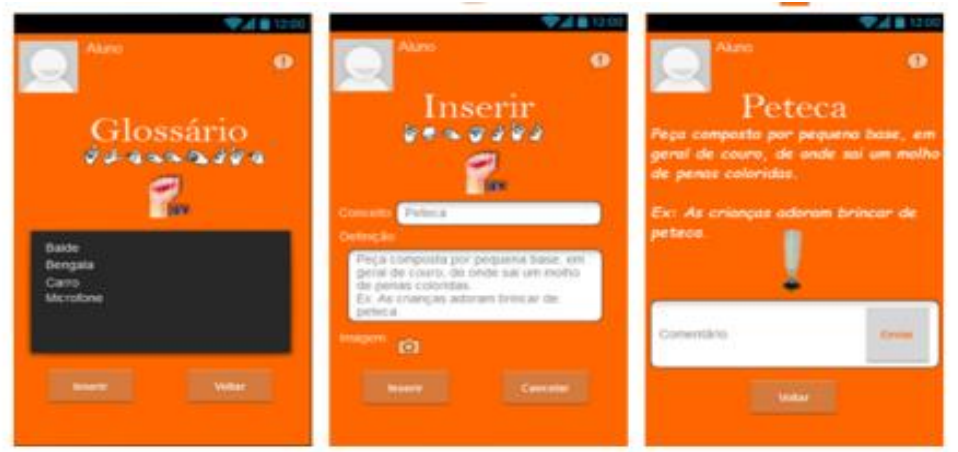

Figura 5. Telas do aplicativo Glossário [Moura e Oliveira 2014].

A ferramenta contribui com a disciplina de língua portuguesa ajudando o professor a ministrar atividades em grupos, ao utilizar a ferramenta o aluno pode buscar as palavras em português ou por meio de imagens.

A Tabela 1, a seguir descreve e compara os aplicativos em relação a algumas funcionalidades utilizadas para comunicação e interação com os usuários. Reforçando que os aplicativos para aprender libras aqui descritos foram pesquisados no Google play.

Tabela 1: Comparação dos aplicativos.

\begin{tabular}{|c|c|c|c|c|c|c|}
\hline \multirow[b]{2}{*}{ Aplicativos } & \multicolumn{6}{|c|}{ Descrição/ Funcionalidades } \\
\hline & Alfabeto & Números & Cores & Ações & Objeto & Internet \\
\hline EduLib & Imagem & Imagem & Gif & Gif & Gif & Off \\
\hline Fala Libras & Imagem & & Imagem & & & On \\
\hline $\begin{array}{l}\text { Alphabet for deaf- } \\
\text { mutes }\end{array}$ & Imagem & & & & & Off \\
\hline $\begin{array}{l}\text { Sinalário } \\
\text { Disciplinar em } \\
\text { Libras }\end{array}$ & Vídeo & Vídeo & Vídeo & & & On \\
\hline Glossário & Imagem & Imagem & & & & Off \\
\hline
\end{tabular}


VII Congresso Brasileiro de Informática na Educação (CBIE 2018)

Anais dos Workshops do VII Congresso Brasileiro de Informática na Educação (WCBIE 2018)

Após analisar os aplicativos na Tabela 1, percebeu-se que todos eles disponibilizam como aprendizado, apenas o alfabeto, números e cores, entretanto, todos eles ensinam o básico que é o alfabeto como uma ferramenta de apoio para surdos. Já o Sinalário Disciplinar do Libras possui imagens e vídeos, porém, ele se baseia nas matérias escolares, sendo uma ferramenta de apoio mais ampla.

A vantagem do EduLib diante desses outros aplicativos além de aprenderem o "alfabeto", "números" e "cores" podem aprender algumas "ações", como "obrigado", "por favor", entre outros, e também "objetos escolares". Outra característica e vantagem seria não necessitar de internet, destinado para quem deseja aprender o básico dentro da escola e até fora dela, em outros ambientes.

\section{EduLib}

Segundo Laurindo e Souza (2017) o giz de cera e o quadro não possui mais atrativos, onde a escola deve conduzir as suas aulas utilizando o Smartphone, Tablets e Notebooks que são tecnologia móveis que possui um uso muito grande pelas crianças e adolescentes, os aplicativos móveis estão mais presente no dia a dia, e utilizando esses tipos de dispositivos com os aplicativos educativos podem auxiliar na educação.

Neste contexto, o EduLib tem como objetivo colaborar no ensino e aprendizado de forma mais simples dos alunos do Atendimento Educacional Especializado, facilitando a comunicação entre as pessoas e ajudando no desenvolvimento mediante a memorização das imagens e gifs.

O Aplicativo EduLib traz também uma contribuição para o aprendizado dos alunos das escolas do ensino fundamental que utilizam as Salas de Recursos Multifuncionais, além de todos que pretendem aprender, assuntos básicos do cotidiano escolar utilizando a linguagem de sinais.

O aplicativo EduLib versão 1.0 é um protótipo que possui cinco categorias com imagens ilustradas para atrair o usuário e os gifs para auxiliar nas comunicações mais difíceis de entender, necessitando uma forma diferente de aprendizado, assim colaborando na intercomunicação com as pessoas com surdez.

Na Figura 6, vimos o menu principal do EduLib com cinco opções de botões, ao selecionar a categoria desejada do aplicativo, terá outras telas de acordo com a categoria desejada, as categorias a serem escolhidas são o "alfabeto", "números", "cores", "ações" e "objetos", todos referentes a conteúdos escolares na língua brasileira de sinais.

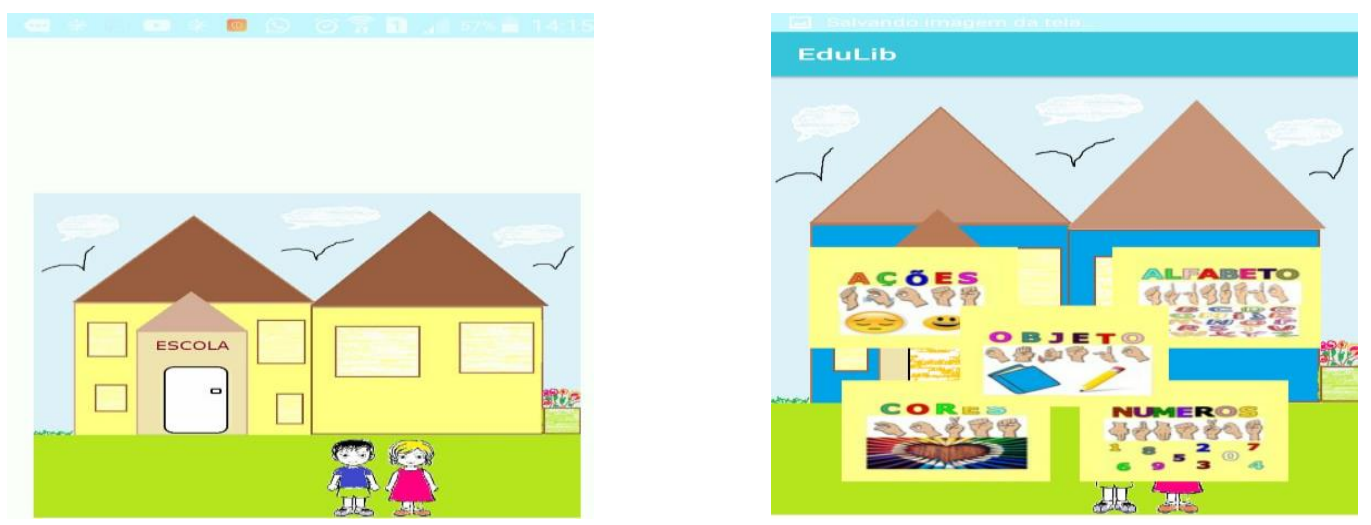

Figura 6. EduLib tela de entrada e Menu Principal. 
VII Congresso Brasileiro de Informática na Educação (CBIE 2018)

Anais dos Workshops do VII Congresso Brasileiro de Informática na Educação (WCBIE 2018)

A Figura 7, apresenta a categoria "alfabeto" que ao ser escolhido mostra as 26 letras do alfabeto A-Z possuindo nas imagens ilustrativas as letras e o alfabeto em libras para atrair o usuário. Eles podem voltar para a letra anterior por meio do ViewPager que é a passagem de uma imagem para a outra.

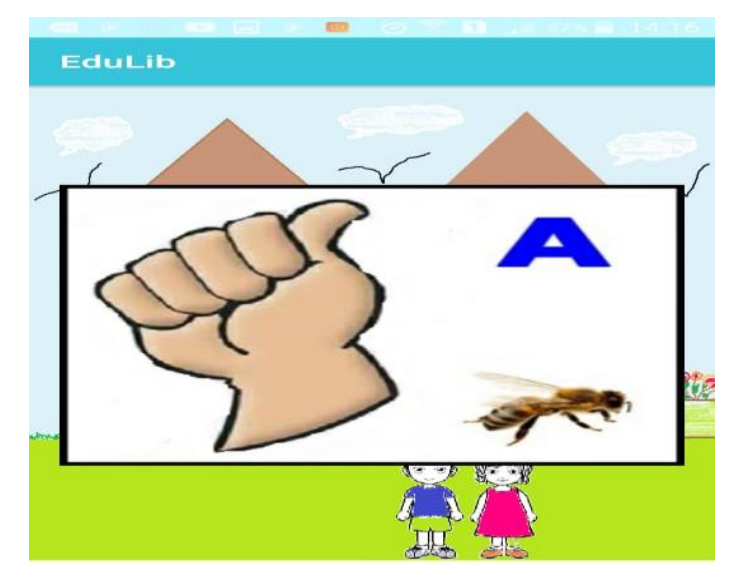

Figura 7. EduLib tela da classe ou categoria do alfabeto.

Na Figura 8, apresenta a categoria "números", ao ser escolhido mostrará os números de 0-9 possuindo nas imagens ilustrativas os números na linguagem de libras para motivar o usuário a aprender os números na linguagem de sinais. Da mesma forma que a categoria "alfabeto", as imagens podem ser movimentadas para o lado e para o outro.

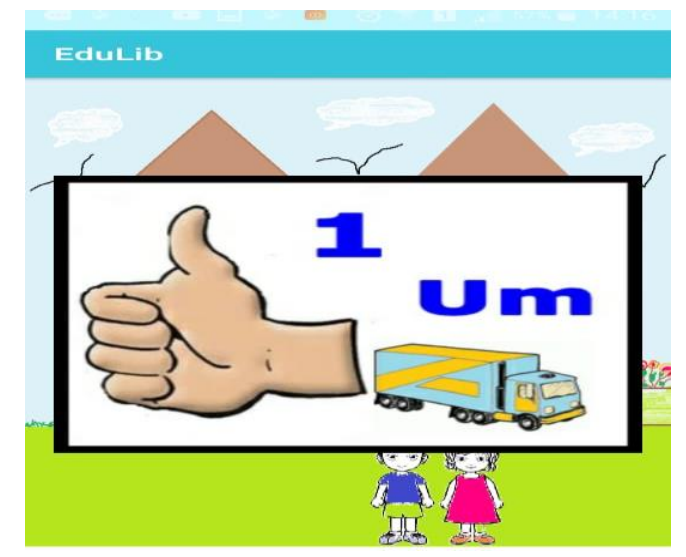

Figura 8. EduLib tela da classe ou categoria números.

Na Figura 9, apresenta a categoria "cores", onde possui 15 botões, onde cada botão possui suas respectivas cores, ao ser clicado será levado para visualizar os gestos de comunicação sobre a cor selecionada por meio de gifs, os gifs foram feitos utilizando o GifImageView onde permite repetir os gestos. Esses gifs são repetidos enquanto o usuário estiver visualizando, e para escolher outras cores o usuário deverá voltar e clicar novamente na cor desejada. 
VII Congresso Brasileiro de Informática na Educação (CBIE 2018)

Anais dos Workshops do VII Congresso Brasileiro de Informática na Educação (WCBIE 2018)
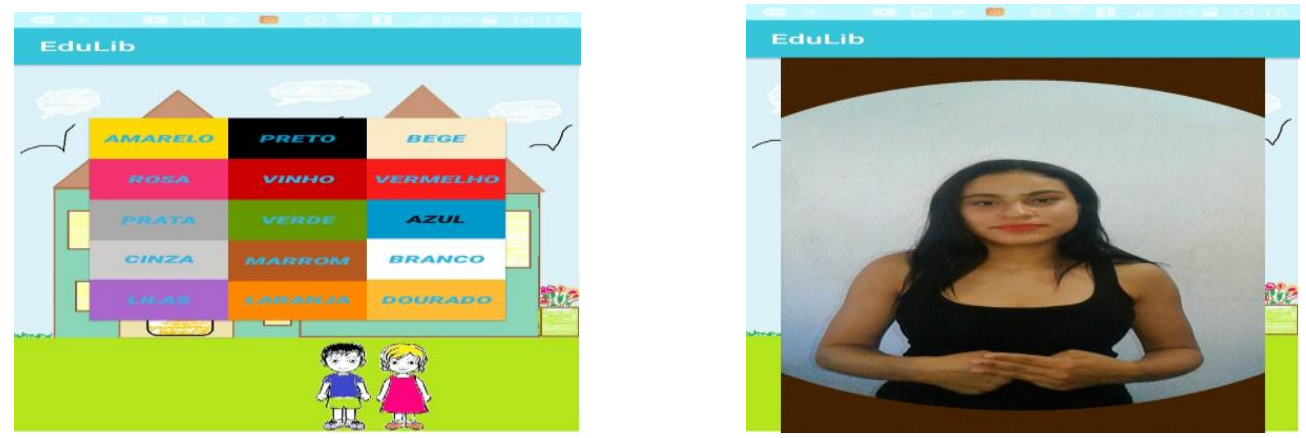

Figura 9. EduLib tela da categoria cores.

A Figura 10, apresenta a categoria "ações" que possui 9 botões, onde cada botão possui suas respectivas ações básicas do dia a dia, ao ser clicado será levado para visualizar os gestos de comunicação por meio dos gifs, e para escolher outras ações o usuário deverá voltar e clicar novamente na ação desejada. Da mesma maneira que a categoria "cores" os gifs são repetidos durante a visualização.
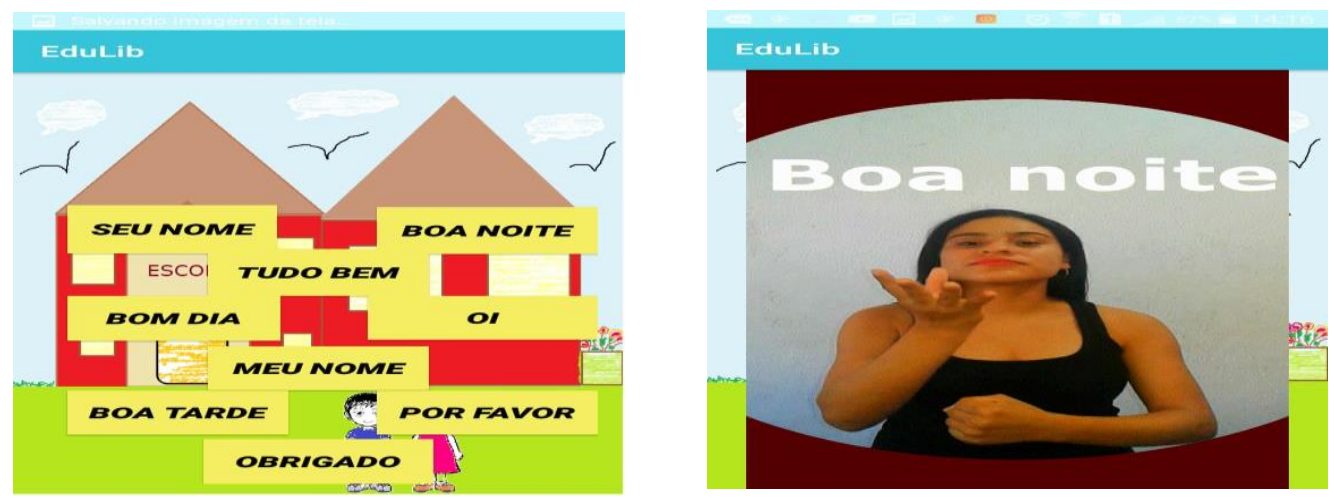

Figura 10. EduLib tela da categoria ações.

A Figura 11, apresenta a categoria "objetos", que possui 10 botões, onde cada botão possui seus respectivos objetos utilizados na sala de aula, ao ser clicado será levado para visualizar os gestos de comunicação por meio de gifs, esses gifs são repetidos enquanto o usuário estiver visualizando, e para escolher outros objetos $\mathrm{o}$ usuário deverá voltar e clicar novamente no objeto desejado.
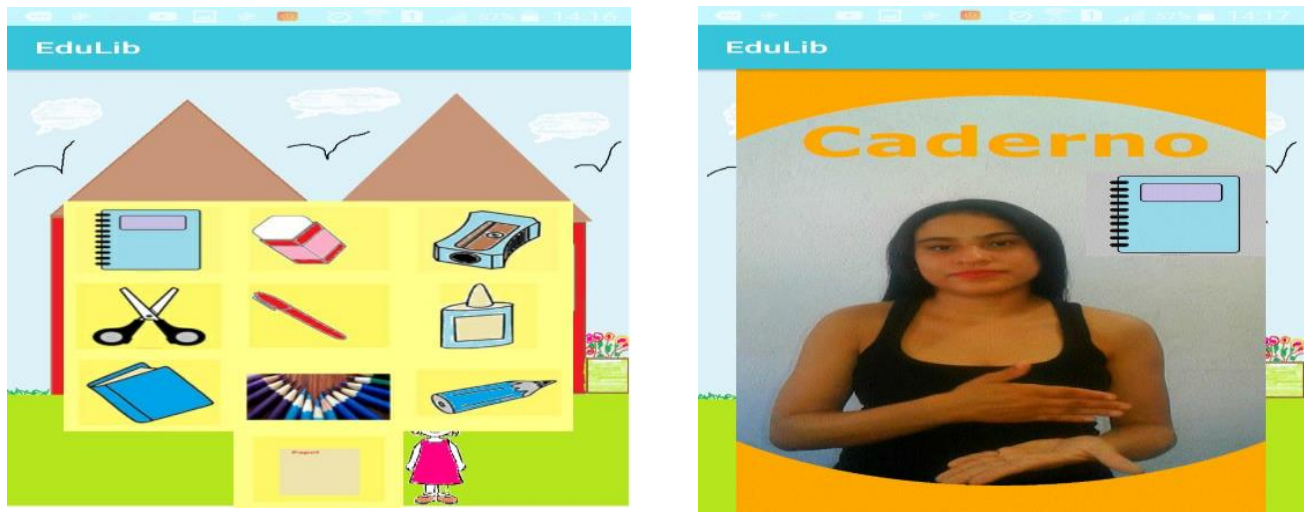

Figura 11. EduLib tela da categoria objetos. 
VII Congresso Brasileiro de Informática na Educação (CBIE 2018)

Anais dos Workshops do VII Congresso Brasileiro de Informática na Educação (WCBIE 2018)

Uma versão inicial do Aplicativo foi disponibilizada online, para realizar o download do aplicativo, acessar o link a seguir: https://www.dropbox.com/sh/g3r2bi6lca82fen/AACzz341As9VJKdKRKqZjN0Ca?dl=0. Um vídeo demonstrativo do aplicativo EduLib encontra-se disponível no link a seguir: https://youtu.be/Bd4f59waj3Y.

\section{Resultados}

Foi realizado um levantamento na secretaria municipal de educação do município de Marabá-PA para identificar quais escolas continham Sala de Recursos Multifuncionais, desse levantamento três escolas foram escolhidas para análise. A Escola Salomé Carvalho e Escola Gaspar Viana localizadas na Folha 16, e Escola Jonathas Pontes Athias localizada na Folha 22, todas retrataram dificuldades em manter um espaço adequado para as Salas de Recursos Multifuncionais (SRMF) com tecnologias assistivas para atendimento dos alunos que precisam utilizar essas salas.

A pesquisa foi realizada em dois momentos, no ano de 2016 e no ano de 2018 , para verificar quais recursos de tecnologias assistivas existiam nas Salas de Recursos Multifuncionais nesses dois períodos.

Os recursos para coleta de dados usados na primeira pesquisa realizada em 2016, foi um aparelho celular utilizado como gravador, e nesse primeiro momento foram realizadas algumas perguntas sobre como funcionava a sala e quais os recursos tecnológicos utilizados e disponíveis dentro das Salas de Recursos Multifuncionais.

Na segunda pesquisa realizada em 2018, foram utilizados um aparelho celular e um questionário com 13 perguntas para realizar a coleta de dados. O questionário foi elaborado com o intuito de verificar se ocorreu mudanças em relação a quantidade de recursos de tecnologias assistivas disponíveis nas Salas de Recursos Multifuncionais, além de verificar de que forma esses recursos estavam sendo utilizados para ajudar as pessoas com deficiências, especialmente pessoas com surdez.

Os resultados obtidos em relação a quantidade de recursos de tecnologias assistivas disponíveis nas Salas de Recursos Multifuncionais não alteraram muito de um período para o outro.

A Escola Salomé Carvalho continua com os mesmos quatro computadores que já possuíam no ano de 2014, dois para o Ensino Fundamental e dois para o Ensino Médio, ambos ficam na mesma Sala de Recursos Multifuncionais, e atualmente também possuem duas impressoras, esses equipamentos foram enviados pelo ministério da educação por meio do programa MEC/FNDE. Os computadores continham instalados o software "Dosvox" que é um aplicativo para pessoas com deficiência visual, e também o software "Cultivar" que é um jogo educativo sobre colheitas e plantações em fazendas, que também é utilizado pelos alunos das salas comuns.

$\mathrm{Na}$ Escola Jonathas Pontes Athias a Sala de Recurso Multifuncional mudou, pois, não contém a mesma quantidade de computadores que tinha no ano de 2014, que eram quatro computadores e atualmente possui apenas um computador com os mesmos softwares instalados o "Dosvox" e o "Cultivar". Entretanto, a escola agora é um centro para a atender pessoas com surdez, além de outras pessoas que necessitam de formação em Libras para melhorar a comunicação com as pessoas surdas.

A Escola Gaspar Viana no período do levantamento no ano de 2018 possuía um 
VII Congresso Brasileiro de Informática na Educação (CBIE 2018)

Anais dos Workshops do VII Congresso Brasileiro de Informática na Educação (WCBIE 2018)

computador para o Ensino Fundamental na Sala de Recursos Multifuncionais, e dois notebooks enviados pelo Ministério da Educação, que não são utilizados por falta de manutenção, além duas máquinas em Braille que não estavam funcionando, precisando de manutenção junto com os notebooks.

Foi observado que as Salas de Recursos Multifuncionais das escolas pesquisadas precisam de mais investimento para aquisição de novos recursos, bem como a realização da manutenção dos recursos já existentes. Além de treinamento especializado para os professores que utilizam em salas.

Os professores das escolas pesquisadas relataram que continuam sem saber manusear alguns aplicativos para trabalhar com os alunos, e questionam sobre a falta de treinamento especializado para conhecerem os softwares e aplicativos, com isto, acaba causando alguns transtornos que desestimulam o uso dos aplicativos.

Foi observado do relato dos professores pesquisados, que eles acreditam que a utilização de ferramentas de apoio são apropriadas para a utilização com os alunos da Sala de Recursos Multifuncionais, também acreditam que essas ferramentas deveriam ser de apoio simples, deveria conter imagens de fácil identificação e visualização com o alfabeto e números em libras.

Observou-se que a maioria dos aplicativos ou outras ferramentas de mídia tecnológica como apoio de aprendizagem necessitam de internet, os professores mencionaram que gostariam que os aplicativos não necessitassem de internet para conseguirem utilizar. Mencionaram também que as ferramentas de apoio apresentam em partes funcionalidades para os alunos com surdez, pois seria interessante uma ferramenta com algo a mais, que possa ser direcionada a cada faixa etária e necessidades de cada pessoa.

Por meio desta pesquisa percebeu-se a necessidade da criação de um aplicativo que pudesse auxiliar e apoiar de alguma forma os alunos que precisam utilizar a SRMF, assim decidiu-se criar um aplicativo via Android para celular, pois foi percebido que na escola Jonathas Pontes Athias a Sala de Recursos Multifuncionais não possui tanto recursos tecnológicos mesmo sendo o Centro de Atendimento Especializado na área da surdez e interpretação em Libras, e por ter sido constatado durante as entrevistas e nos resultados do questionário que os alunos utilizam mais seus celulares como meio de comunicação e aprendizagem.

\section{Conclusão}

A tecnologia assistiva é uma ferramenta de apoio para solucionar os problemas com o aprendizado de pessoas com deficiência, além de possibilitar uma qualidade de vida melhor, pode ser utilizada com as crianças ou com qualquer pessoa que necessite, onde irá ajudá-los a superarem, progredirem e a conquistarem seus objetivos.

Diante do exposto, o aplicativo mobile EduLib foi projetado para auxiliar no ensino-aprendizagem das crianças com surdez, podendo ser utilizados nas escolas do ensino Fundamental, para as crianças aprenderem de forma mais divertida, além de possibilitar outras pessoas que tenham interesse em conhecer e aprender a língua de sinais.

O aplicativo disponibiliza cinco categorias ou classes diferentes de opções, nos 
VII Congresso Brasileiro de Informática na Educação (CBIE 2018)

Anais dos Workshops do VII Congresso Brasileiro de Informática na Educação (WCBIE 2018)

quais os professores poderão utilizar na SRMF com seus alunos o "alfabeto", "números" e "cores", além de "objetos" e "ações" que são utilizados durante dia a dia na escola.

Esta aplicação possibilita aproveitamento do uso de tecnologia mobile dentro da SRMF auxiliando os professores e os alunos, sendo necessário a utilização do celular que é um recurso tecnológico mais usado pelos alunos e professores, bastando apenas que o celular contenha o sistema operacional Android.

Com a utilização do aplicativo espera-se que possa trazer uma colaboração para a educação, relacionada ao ensino fundamental e para os professores da escola, fazendo a conexão entre o ensino e aprendizagem, pois tem uma função de apoiar o básico, pois é uma ferramenta simples, sendo capaz de ser utilizado não somente nas SRMF, mas também para quem deseja aprender um pouco a linguagem brasileira de sinais (Libras).

Portanto após levantarmos a realidade dessas escolas, em relação a utilização de recursos de tecnologias assistivas dentro das SRMF, o aplicativo mobile possibilita auxiliar no processo de ensino aprendizagem, permitindo acesso ao conhecimento básico de libras, promovendo a interação entre os estudantes e membros da escola, que necessitam comunicar-se com as crianças, e além de ser um aplicativo direcionado as crianças que estão no ensino fundamental e em início de aprendizado na área bilingue, melhorando o "aprender", a comunicação, a interação com as outras pessoas.

Como o EduLib é um protótipo, como trabalhos futuros serão realizados vários testes da ferramenta para implantá-las nas escolas pesquisadas, para a sua utilização dentro das SRMF, além de disponibilizar um manual de usuário em conjunto com a ferramenta por perceber que os professores possuem dificuldades em manusear qualquer ferramenta para trabalhar com os alunos com necessidade especiais.

\section{Referências}

Google Play (2018). Disponível em: <https://play.google.com/store>. Acesso em 10 de março de 2018.

Laurindo, A K S; Souza, P H S. (2017). Aplicativos Educacionais: Um estudo de caso no desenvolvimento de um aplicativo na plataforma App Inventor2 para auxilio no ensino de produção textual nas aulas de Português. UFSC.

Moura, E. R. S; Oliveira, E. H. T. Uma ferramenta colaborativa móvel para apoiar o processo de ensino-aprendizagem da LIBRAS e do Português para surdos. $3^{\circ}$ Congresso Brasileiro de Informática na Educação (CBIE 2014) Workshops (WCBIE 2014).

Rocha, A. N. D. C. (2010). Processo de prescrição e confecção de recursos de tecnologia assistiva na educação infantil. 2010. 199f. Dissertação (Mestrado em Educação)Faculdade de Filosofia e Ciências, Universidade Estadual Paulista, Marília.

Rodrigues, M. (2013). Avaliação da Tecnologia Assistiva na Sala de Recursos Multifuncionais: Estudo de Caso em Fortaleza-Ceará. Dissertação-Universidade Federal do Ceará, Programa de Pós-Graduação em Educação Brasileira, Fortaleza. 